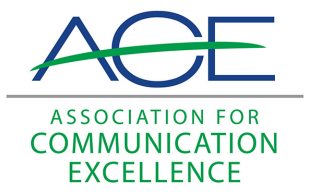

Journal of Applied Communications

\title{
A Content and Visual Analysis of Promotional Pieces Used in a Communication Campaign for the Arkansas [Commodity] Promotion Board
}

Amy Hughes

Tara L. Johnson

Leslie D. Edgar

See next page for additional authors

Follow this and additional works at: https://newprairiepress.org/jac (c) (i) (2)

This work is licensed under a Creative Commons Attribution-Noncommercial-Share Alike 3.0 License.

\section{Recommended Citation}

Hughes, Amy; Johnson, Tara L.; Edgar, Leslie D.; Miller, Jefferson D.; and Cox, Casandra (2016) "A Content and Visual Analysis of Promotional Pieces Used in a Communication Campaign for the Arkansas [Commodity] Promotion Board," Journal of Applied Communications: Vol. 100: Iss. 2. https://doi.org/ 10.4148/1051-0834.1027

This Research is brought to you for free and open access by New Prairie Press. It has been accepted for inclusion in Journal of Applied Communications by an authorized administrator of New Prairie Press. For more information, please contact cads@k-state.edu. 


\title{
A Content and Visual Analysis of Promotional Pieces Used in a Communication Campaign for the Arkansas [Commodity] Promotion Board
}

\begin{abstract}
This study analyzed a communications campaign developed by a third-party communications group (TPCG) for a prominent commodity promotion board in Arkansas. The campaign included numerous promotional pieces targeted to three audience segments: general public, [commodity] producers, and animal agriculture producers. A systematic, content-driven assessment examined message content and visuals used in these creative pieces, comparing the actual messages with intended messages from TPCG's original communications campaign plan. A total of 53 pieces were evaluated, and 27 different communicative themes emerged. Many of the creative pieces used in the campaign displayed multiple messages in a single piece. Celebrity endorsements of [commodity] were the most saturated theme, accounting for $21.01 \%$ of messaging in the general public creative pieces. Promotion of the [commodity] board was the most prominent theme (16.38\%) in the [commodity] producer pieces. Benefits to the Arkansas economy was the most prominent theme (10.73\%) in the animal agriculture creative pieces. Although TPCG predominantly achieved consistency through messages that aligned with its campaign plan, a portion of the promotional pieces across all audiences did not contain messages that were a part of the original plan. Therefore, more than one-third (38.1\%) of the messages found in the creative pieces were deemed inconsistent or inconclusive. The researchers recommend utilizing a needs assessment to aid in identifying appropriate messaging, and testing those messages through standard evaluation procedures.
\end{abstract}

\section{Keywords}

Agricultural Communications, Communication Campaigns, Content and Visual Analysis, Messages, Target Audiences

\section{Authors}

Amy Hughes, Tara L. Johnson, Leslie D. Edgar, Jefferson D. Miller, and Casandra Cox 


\title{
A Content and Visual Analysis of Promotional Pieces Used in a Communication Campaign for the Arkansas [Commodity] Promotion Board
}

\author{
Amy Hughes, Tara L. Johnson, Leslie D. Edgar, \\ Jefferson D. Miller and Casandra Cox
}

\section{Abstract}

This study analyzed a communications campaign developed by a third-party communications group (TPCG) for a prominent commodity promotion board in Arkansas. The campaign included numerous promotional pieces targeted to three audience segments: general public, [commodity] producers, and animal agriculture producers. A systematic, content-driven assessment examined message content and visuals used in these creative pieces, comparing the actual messages with intended messages from TPCG's original communications campaign plan. A total of 53 pieces were evaluated, and 27 different communicative themes emerged. Many of the creative pieces used in the campaign displayed multiple messages in a single piece. Celebrity endorsements of [commodity] were the most saturated theme, accounting for 21.01\% of messaging in the general public creative pieces. Promotion of the [commodity] board was the most prominent theme (16.38\%) in the [commodity] producer pieces. Benefits to the Arkansas economy was the most prominent theme (10.73\%) in the animal agriculture creative pieces. Although TPCG predominantly achieved consistency through messages that aligned with its campaign plan, a portion of the promotional pieces across all audiences did not contain messages that were a part of the original plan. Therefore, more than one-third (38.1\%) of the messages found in the creative pieces were deemed inconsistent or inconclusive. The researchers recommend utilizing a needs assessment to aid in identifying appropriate messaging, and testing those messages through standard evaluation procedures.

\section{Key Words}

Agricultural Communications, Communication Campaigns, Content and Visual Analysis, Messages, Target Audiences

\section{Literature Review}

With the average consumer being more than three generations removed from the farm (Arkansas Farm Bureau, n.d.), the need for agricultural literacy is evident (Igo \& Frick, 1999; Ryan \& Lockaby, 1996). While consumer influence on agricultural production continues to grow, consumer perception of marketing and agriculture is poor. A Delphi study completed by Frick, Birkenholz, and Machtmes (1995) found that both rural and urban adults' perceptions regarding marketing and plant science were less positive than their perceptions of other agricultural topics. Consumers need to be "agriculturally literate" in order to respond appropriately as issues

Some content in this article was purposely left without identifiers. Namely, the commodity under study and the Third Party Communications Group. This was necessary due to the nature of funding that supposs, 2017 this research. 
arise (Frick et al., 1995, p. 44). Individuals who respond to agricultural issues without a basic understanding of all sides are more likely to react without reason. A better understanding of agriculture and its practices is needed to create "more effective educational and informational messages that increase the public's understanding of these complex agricultural issues" (Doerfert, 2011, p. 13). As a result, several agricultural commodity groups have developed communications campaigns to promote their products (Arkansas [Commodity] Promotion Board [ACPB], 2011a; California Milk Advisory Board [CMAB], 2013; Cotton Incorporated, 2013). Agriculture companies must effectively communicate with their current and potential customers and evaluate the impact and effect their communications and marketing campaigns have on a targeted audience (Weinreich, 2010). In addition, evaluation is essential in establishing campaign effectiveness.

In an effort to meet demands, new relationships between food producers, processors, and retailers have been established through improved marketing communications (MacDonald et al., 2004). The primary role of marketing communications is to engage audiences, and promote the organization through a variety of communication tools (Hanstén, 2009). Integrated Marketing Communications (IMC) is a popular approach to engaging audiences while communicating key marketing messages. IMC is described as a "strategic approach to communicating the brand and its message to targeted audiences in ways that are clear, concise, and consistent" (Marshall \& Johnston, 2010 , p. 9). For the purposes of this study, the definition of message is an "explicit reference to attributes via verbal or visual content" (Laczniak \& Muehling, 1993, p. 328).

Public figures or celebrities are often used in marketing campaigns to establish credibility (Weinreich, 2011) with an audience. An association with a celebrity achieves a higher degree of responsiveness and recollection (Schlecht, 2003); and increases awareness of a company's advertising by forming positive feelings toward brand attitude and purchase intentions (Agrawal \& Kamakura, 1995; Kamins, Brand, Hoeke, \& Moe, 1989; Khatri, 2006; Knapp, 1994). To achieve a higher impact, celebrities should appeal to the targeted consumers. The goal of employing endorsers should be to increase marginal value and "enhance brand equity by means of 'second association' of a celebrity with a brand” (Agrawal \& Kamakura, 1995, p. 56).

Typically, a communication campaign is "an organized communication activity, directed at a particular audience, for a particular period of time, to achieve a particular goal” (Snyder, 2003, p. 167). Communication campaigns have existed for hundreds of years, but agriculture, over the past several decades, has focused on improving and expanding campaign development and use. Telg and Irani (2012) described a communications campaign as "a strategic, structured plan consisting of a mix of media and message strategies and tactics with a consistent, unified theme" (p. 306). Successful campaigns are normally preceded by a planning phase. The plan should outline tasks via clear steps based on carefully developed strategies and tactics to achieve objectives and should conclude with plans for evaluation. Telg and Irani (2012) outlined specific steps to campaign development: (1) client profile, (2) audience analysis, (3) campaign objectives, (4) situational analysis, (5) SWOT analysis, (6) strategies, (7) tactics, and (8) media objectives, strategies, and tactics.

Telg and Irani's (2012) steps provide agricultural marketing communications professionals with a structure to aid in campaign evaluation. Campaign evaluation, or assessment, is an important portion of the IMC model, because assessments provide evidence of success and failure, allowing communicators to make adjustments to the campaign (or to future campaigns) to improve effectiveness. Campaign assessments are systematic collections and analyses of information 
about the activities, outcomes, and impacts to specific target audiences in an effort to improve effectiveness (Patton, 1982; Rice \& Atkin, 2013). In the IMC process, it is necessary to evaluate the impact and effect that a campaign has on specific target audiences, or "people whose behavior you wish to affect" (Weinreich, 2010, p. 9). The overall success of the campaign is determined by the effect on a specified target audience, and assessments should compare the outlined campaign goals with the achieved campaign goals (Hanstén, 2009; Rice \& Atkin, 2013).

\section{Theoretical and Conceptual Framework}

Mass communications, as implied by the name, are designed to reach the mass, potential audiences, which are difficult to reach because of their relative vagueness. "Potential audiences are viewed as large aggregates of anonymous consumers, and the relationship between the sender and receiver is affected accordingly" (McQuail, 2005, p. 55). Mass communication messages are often repurposed in identical forms, resulting in oversaturation in the media and loss of uniqueness (McQuail, 2005). In the typical mass communication model, the audience (the general public) is widely dispersed. Usually, a mass media campaign's "primary purpose is to advance an interest or opinion and to achieve a change" among this widely dispersed audience (McQuail, 2005, p. 56).

Content analysis is a common approach to evaluating mass communication campaigns and methods. Content analysis is a systematic, replicable technique where many words of text are compressed into fewer content categories based on rules of coding (Edgar \& Rutherford, 2012). Content analysis works especially well in evaluations involving images as well as textual content. When the combination of words and images is used effectively, it becomes one of the strongest forms of communication (Lester, 2011). Therefore, analyzing both text and images in a campaign should result in a comprehensive evaluation.

Images are often an important part of marketing campaigns, and content analysis using semiotic theory is a logical part of evaluating an IMC (Lester, 2011; Wimmer \& Dominick, 2003). Perceptions and meanings of images often depend on how individual audience members interpret elements in the image and on what emotions the image elicits (Manghani, 2013). Semiology is the study of images and the signs and symbols within them (Tolbert \& Rutherford, 2009). The categorization of images in communications campaigns provides a conceptual framework for interpreting connotative and denotative values, an approach that can be attributed to semiotics theorist Roland Barthes (Caywood \& Langrehr, 1995; Edgar \& Rutherford, 2012). Denotation, the first layer of analysis, is an individual's first reaction when looking at the image (Lester, 2011). The second layer of analysis, connotation, is what the objects in the image represent. Barthes' concepts of connotation and denotation provided the basis for much of the visual analyses within this study. Understanding both content and visual content in campaign materials is the only way to determine how messaging may be impacting audience members. Agricultural communication campaign evaluations are critical to understand campaign breadth and depth, and their results lead to the necessary steps for message improvement.

\section{Need for the Study}

The need for this study was supported by two research priority areas outlined in the National Research Agenda (NRA): (1) aiding the public in participating in decision making related to agriculture, and (2) improving public and policy maker understanding of agriculture and natural resources (Doerfert, 2011). Within these priority areas, the NRA defined a need to increase 
understanding of the effectiveness of messaging and educational programs within agriculture. As generations become further removed from the farm, outlets that provide agricultural knowledge or increase agricultural literacy are imperative (Reidel, Wilson, Flowers, \& Moore, 2007). Some of this agricultural literacy is being delivered to the public in the form of communication campaigns focused on branding products or services.

Agricultural commodity group marketing communications campaigns often focus on improving audiences' agricultural knowledge and literacy, and these efforts must be evaluated to determine the success of the commodity groups' investments. The commodity group that underwrote this study recognized the need for its marketing campaign to be evaluated and commissioned the researchers to conduct an independent evaluation of its recent marketing communications efforts. As a part of this research, the organization has asked to remain anonymous.

\section{Purpose and Objectives}

The purpose of this study was to evaluate promotional pieces used in a communications campaign developed for the Arkansas [Commodity] Promotion Board (ACPB) through content and visual analyses. The promotional pieces were produced and disseminated by a third-party communications group (TPCG) to reach three target audiences, namely the general public, [commodity] producers, and animal agriculture producers. Promotional pieces included (a) website, (b) booth display, (c) educational videos, (d) electronic newsletters, (e) radio \& television segments, (f) press releases and event programs, (g) print and banner advertisements, and (h) logos.

The following objectives guided the study:

1. Determine the written content used in promotional pieces targeting the three outlined audience groups.

2. Determine the visual content used in promotional pieces targeting the three outlined audience groups.

3. Compare the content and visual messages used in promotional pieces targeting the three outlined audience groups.

\section{Methodology}

\section{Study Design and Content Analysis Methods}

This study used a content and visual analysis based on semiotic theory to analyze communications campaign promotional pieces developed for a large state commodity board. The general public, animal agriculture producers, and [commodity] producers were identified in the third-party communication group's (TPCG) 2012 campaign as target audience groups. With these intended audiences in mind, the campaign was evaluated in a systematic, content-driven approach to assess the potential impact on perceptions of individuals (Edgar \& Rutherford, 2012).

Per the agreement reached by the commodity board and the marketing communications firm, TPCG, the firm provided 53 promotional pieces to be evaluated. Each promotional piece was not targeted to all audiences; however, some promotional pieces were targeted to promote to multiple audiences. Of the total promotional pieces created $(N=53), 42$ were used to target the general public audience, 33 to target the [commodity] producers, and 11 to target animal agriculture producers who purchase the commodity as a feed ingredient. 
The researchers in this study (evaluation team) performed a comprehensive qualitative evaluation of the campaign deliverables produced by TPCG. Qualitative data analysis is "primarily an inductive process of organizing data into categories and identifying patterns and relationships among the categories" (McMillan \& Schumacher, 2010, p. 367). The researchers in this study used inductive analysis to synthesize and make meaning from the data in the campaign deliverables by identifying categories and patterns (McMillan \& Schumacher, 2010).

For textual messages, a code sheet, created by the researchers, was used to analyze creative materials that contained copy. Video transcripts were also analyzed by the same method. Through a systematic and replicable process (Edgar \& Rutherford, 2012), the textual materials were analyzed for keywords in context, and emergent themes were identified and then compressed into categories based on specific coding rules (Edgar \& Rutherford, 2012; Gall, Gall, \& Borg, 2006; Lincoln \& Guba, 1985; Gibbs, 2007). Words and passages were coded in their original context (Creswell, 1998), and key themes emerged that characterized the promotional pieces and their corresponding intended messages used to target the general public, [commodity] producers, and animal agriculture producers. These three audience groups were the specific audiences targeted in the TPCG communication plan, not ones noted by the researchers of this study. Emergent themes were compressed based on peer debriefing between the student researchers and a panel of experts. This was used to reinforce the data's accuracy and reach intercoder agreement (Creswell, 2009; Gibbs, 2007).

A visual coding sheet, created by the researchers, was used to assess promotional materials that used images or visual elements (e.g., print advertisements, photos, and videos). The visual materials were analyzed denotatively. The contents of the images were broken down by what the researchers' immediately saw when looking at the image. Next, the objects in the images were analyzed for connotation to determine associative value of the photo (Edgar \& Rutherford, 2012). "For example, an image of a tropical island would have a basic denotative reading of a tropical location, and a possible connotative reading of a vacation or relaxation" (Rhoades \& Irani, 2008, p. 36). This approach created an account of how the meanings within images from the campaign were perceived (Rose, 2012). Lutz and Collins (1993) suggested that, if the images are coded carefully, a content analysis could be used to interpret the cultural meanings of images. Similarly, the video code sheet guided the researchers through identifying the denotative and connotative values of the visual representations in each video.

Emergent themes were combined to produce an outlined message that the audience could have interpreted from the piece. Emergent thematic messages, identified by the researchers for each creative piece, were then compared with the intended message outlined by TPCG in its 2102 campaign plan document. This process was used to determine message consistency for each promotional piece. Message consistency was categorized into three evaluative characteristics: (a) content message consistency, (b) visual message consistency, and (c) content versus visual message consistency. For content consistency, the message identified from the content analysis, or implied message, was compared to the original message outlined by TPCG. The visual message consistency was determined by comparing the identified message from the visual analysis to the original intended message outlined by TPCG. It was possible that one creative piece fell into both content and visual for analyses. Content versus visual message consistency was evaluated by comparing the implied content analysis to the implied visual analysis message. This process was used to determine if the print and visual message complemented each other as opposed based on comparison to the original message outlined by TPCG. 


\section{Coder Training and Reliability}

Before proceeding with the content evaluation of the campaign, the researchers independently assessed four creative pieces: a print ad, logo, press release, and event sign. Then the researchers compared their individual analyses, checked their agreement, and established a percentage of reliability. This process was repeated until the researchers' consistently averaged more than 70\% agreement in their interpretations (McMillan \& Schumacher, 2010). Usually, there is a level of consensus between qualitative researchers, but, often, the way the researchers individually identify themes was different (Armstrong, Gosling, Weinman, \& Marteau, 1997). The student researchers, in this study, originally identified similar themes in different ways, but after discussion and repeated analyses, agreement and like-mindedness were achieved. Through this process, assessment criteria were defined and redefined to increase consistency and aid in replication of this study. Doing so, according to Rose (2011), ensured that two coders using the same set of codes could produce the same results from the same set of images. Ultimately, because the researchers found a high level of agreement, with an inter-rater reliability of $87.5 \%$, they established consistency in their evaluation (McMillan \& Schumacher, 2010). A panel of faculty advisors consisting of two agricultural communications professors and one instructor oversaw this process.

\section{Results and Findings}

\section{Content Analysis}

Four television spots, one educational video, five radio spots, two webisodes, four public service radio spots, three print advertisements, two banners, two e-News documents, five blogs, one infographic, one booth display, six recipes, four signs, one flyer, and one press release were used to target the general public. Promotional pieces used to target [commodity] producers, included four television spots, one educational video, five radio spots, two webisodes, three print advertisements, three banners, three e-News documents, five blogs, one infographic, one booth display, six recipes, three signs, one press release, website, table top signage, and five giveaways. There were two television spots, one educational video, two radio spots, one print advertisement, one display, two signs, and two webisodes targeting animal agriculture producers. 


\section{General public.}

Twenty-seven unique themes with 771 themes occurrences emerged from the analysis of content pieces within the general public group. All emergent themes are listed in Table 1 by frequency order. Celebrity endorsements was the most saturated theme with $21.01 \%$ in the general public target audience.

\section{Table 1}

Emergent Content Themes and Occurrences Identified in the General Public Promotional Pieces (n = 33)

\begin{tabular}{|c|c|c|}
\hline Content Themes & $N$ & $\%$ \\
\hline Celebrity endorsements & 162 & 21.01 \\
\hline Promotion of board & 102 & 13.23 \\
\hline For use in food products & 66 & 8.56 \\
\hline How $[$ commodity]s are produced & 63 & 8.17 \\
\hline [Commodity]s contribute to Arkansas agriculture & 50 & 6.49 \\
\hline Diversity of [commodity]s & 38 & 4.93 \\
\hline General benefits to Arkansas & 26 & 3.37 \\
\hline Benefits to Arkansas economy & 25 & 3.24 \\
\hline Value of educating about [commodity]s & 23 & 2.98 \\
\hline For use in common household products & 22 & 2.85 \\
\hline Economic value to consumers & 20 & 2.59 \\
\hline Promotion/Use of slogan & 19 & 2.46 \\
\hline [Commodity]s are grown in Arkansas & 18 & 2.33 \\
\hline For use in energy products & 18 & 2.33 \\
\hline For use in animal products & 18 & 2.33 \\
\hline [Commodity]s are healthy for consumers & 18 & 2.33 \\
\hline [Commodity]s are environmentally sustainable & 18 & 2.33 \\
\hline [Commodity]s contribute to animal agriculture & 16 & 2.08 \\
\hline Human benefits & 10 & 1.30 \\
\hline Research is valuable to production & 9 & 1.17 \\
\hline Partnerships are important & 8 & 1.04 \\
\hline [Commodity]s are delicious to consumer tastes & 7 & 0.91 \\
\hline Technology improved production & 7 & 0.91 \\
\hline Bean2Blog is an educational event & 3 & 0.39 \\
\hline For use in industrial products & 2 & 0.26 \\
\hline $\mathrm{ACPB}$ funds post-secondary education & 2 & 0.26 \\
\hline United [commodity] Board Check-off program & 1 & 0.13 \\
\hline Total & 771 & 100.00 \\
\hline
\end{tabular}

\section{[Commodity] producers.}

Twenty-four unique themes and 348 theme occurrences emerged from the analysis of the [commodity] producers' group print materials (Table 2). The most identified theme for this audience was promotion of [commodity] board with $16.38 \%$ saturation of the theme in all promotional pieces used to target this audience. 
Table 2

Emergent Content Themes and Occurrences Identified in the [Commodity] Producers Promotional Pieces $(\mathrm{n}=19)$

\begin{tabular}{|c|c|c|}
\hline Content Themes & $N$ & $\%$ \\
\hline Promotion of [Commodity] board & 57 & 16.38 \\
\hline How $[$ commodity]s are produced & 35 & 10.06 \\
\hline Diversity of [commodity]s & 29 & 8.33 \\
\hline For use in food products & 26 & 7.47 \\
\hline [Commodity]s are grown in Arkansas & 23 & 6.61 \\
\hline Benefits to Arkansas economy & 23 & 6.61 \\
\hline General benefits to Arkansas & 18 & 5.17 \\
\hline Human benefits & 18 & 5.17 \\
\hline For use in energy products & 16 & 4.60 \\
\hline For use in animal products & 16 & 4.60 \\
\hline Promotion/Use of slogan & 14 & 4.02 \\
\hline [Commodity]s contribute to Arkansas agriculture & 12 & 3.45 \\
\hline Technology improves production & 11 & 3.16 \\
\hline Research is valuable to production & 10 & 2.87 \\
\hline [Commodity]s contribute to animal agriculture & 8 & 2.30 \\
\hline For use in common household products & 6 & 1.72 \\
\hline Value of educating about [commodity]s & 5 & 1.44 \\
\hline [Commodity]s are environmentally sustainable & 5 & 1.44 \\
\hline Economic value to consumers & 5 & 1.44 \\
\hline Partnerships are important & 3 & 0.86 \\
\hline For use in industrial products & 3 & 0.86 \\
\hline Celebrity endorsements & 3 & 0.86 \\
\hline $\mathrm{ACPB}$ funds post-secondary education & 1 & 0.29 \\
\hline United [Commodity] Board Check-off & 1 & 0.29 \\
\hline Total & 348 & 100.00 \\
\hline
\end{tabular}

Animal agriculture producers.

Twenty emergent themes with 177 theme occurrences were identified within the animal producers' group promotional material assessments (Table 3). The most commonly identified theme in the promotional pieces for the animal agriculture audience, benefits Arkansas economy had a $10.73 \%$ saturation rate across all print promotional pieces used to target this group. 
Table 3

Emergent Content Themes and Occurrences Identified in the Animal Agriculture

Promotional Pieces $(\mathrm{n}=11)$

\begin{tabular}{lrr}
\hline Content Themes & $N$ & $\%$ \\
\hline Benefits Arkansas economy & 19 & 10.73 \\
Promotion of [commodity] board & 15 & 8.47 \\
For use in food products & 15 & 8.47 \\
Diversity of [commodity]s & 14 & 7.91 \\
For use in animal feed products & 13 & 7.34 \\
For use in energy products & 13 & 7.34 \\
Human benefits & 12 & 6.78 \\
General benefits to Arkansas & 12 & 6.78 \\
[Commodity]s are grown in Arkansas & 12 & 6.78 \\
How [commodity]s are produced & 9 & 5.08 \\
Promotion/Use of slogan & 9 & 5.08 \\
[Commodity] contribute to Arkansas agriculture & 8 & 4.52 \\
[Commodity]s contribute to animal agriculture & 6 & 3.39 \\
For use in common household products & 5 & 2.82 \\
Economic value to consumers & 5 & 2.82 \\
[Commodity]s are environmentally sustainable & 4 & 2.26 \\
Research is valuable to production & 2 & 1.13 \\
For use in industrial products & 2 & 1.13 \\
Technology improved production & 1 & 0.56 \\
United [Commodity] Board Check-off & 1 & 0.56 \\
Total & 177 & 100.00 \\
\hline
\end{tabular}

\section{Visual Analysis}

General public.

Twenty-one unique themes with 232 themes occurrences emerged from the analysis of the visual pieces targeting the general public group. All emergent themes are listed in Table 4 by order of frequency. How [commodity]s are produced was the most saturated theme with $30.17 \%$. 
Table 4

Emergent Visual Themes and Occurrences Identified in the General Public Promotional Pieces ( $\mathrm{n}=23$ )

\begin{tabular}{lcc}
\hline Visual Themes & $N$ & $\%$ \\
\hline How [commodity]s are produced & 70 & 30.17 \\
[Commodity]s are grown in Arkansas & 30 & 12.93 \\
Promotion of [commodity] board & 24 & 10.34 \\
[Commodity]s contribute to animal agriculture & 17 & 7.33 \\
For use in food products & 15 & 6.47 \\
For use in energy products & 11 & 4.74 \\
For use in industrial products & 11 & 4.74 \\
For use in animal products & 9 & 3.88 \\
[Commodity]s contribute to Arkansas agriculture & 7 & 3.02 \\
Celebrity endorsements & 6 & 2.59 \\
Research is valuable to production & 6 & 2.59 \\
Value of educating about [commodity]s & 5 & 2.16 \\
Economic value to consumers & 5 & 2.16 \\
For use in common household products & 4 & 1.72 \\
Diversity of [commodity]s & 3 & 1.29 \\
Bean2Blog is an educational event & 3 & 1.29 \\
[Commodity]s are environmentally sustainable & 2 & 0.86 \\
Partnerships are important & 2 & 0.86 \\
Benefits to Arkansas economy & 1 & 0.43 \\
United [Commodity] Board Check-off program & 1 & 0.43 \\
Total & 232 & 100.00 \\
\hline
\end{tabular}

\section{[Commodity] producers.}

There were 19 different themes and 185 theme occurrences identified within the producers group visual materials (Table 5). The most frequently identified theme in the promotional pieces targeting the [commodity] producers was, how [commodity]s are produced, with $17.30 \%$ saturation across all visual promotional pieces used to target this group. 
Table 5

Emergent Visual Themes and Occurrences Identified in the [Commodity] Producers Promotional Pieces $(\mathrm{n}=23)$

\begin{tabular}{lrr}
\hline Visual Themes & $N$ & $\%$ \\
\hline How [commodity]s are produced & 32 & 17.30 \\
[Commodity]s are grown in Arkansas & 24 & 12.97 \\
Promotion of [commodity] board & 21 & 11.35 \\
Promotion/Use of slogan & 21 & 11.35 \\
For use in food products & 14 & 7.57 \\
[Commodity]s contribute to animal agriculture & 13 & 7.03 \\
For use in industrial products & 10 & 5.41 \\
For use in energy products & 9 & 4.86 \\
For use in animal products & 9 & 4.86 \\
[Commodity]s contribute to Arkansas agriculture & 9 & 4.86 \\
Research is valuable to production & 7 & 3.78 \\
Diversity of [commodity]s & 5 & 2.70 \\
For use in common household products & 3 & 1.62 \\
Benefits to Arkansas economy & 2 & 1.08 \\
General benefits to Arkansas & 2 & 1.08 \\
Value of educating about [commodity]s & 1 & 0.54 \\
[Commodity]s are environmentally sustainable & 1 & 0.54 \\
Partnerships are important & 1 & 0.54 \\
United [Commodity] Board Check-off & 1 & 0.54 \\
Total & 185 & 100.00 \\
\hline
\end{tabular}

Animal agriculture producers.

Sixteen unique themes with 160 theme occurrences were identified in the creative pieces targeting animal agriculture producers (Table 6). The most common emergent theme was how [commodity]s are produced, with $21.58 \%$ saturation of the theme in all visual promotional pieces for this audience.

Table 6 
Emergent Visual Themes and Occurrences Identified in the Animal Agriculture

Promotional Pieces $(\mathrm{n}=9)$

\begin{tabular}{lrr}
\hline Visual Themes & $N$ & $\%$ \\
How [commodity]s are produced & 41 & 21.58 \\
[Commodity]s are grown in Arkansas & 19 & 10.00 \\
[Commodity]s contribute to animal agriculture & 17 & 8.95 \\
Promotion of [commodity] board & 16 & 8.42 \\
For use in food products & 12 & 6.32 \\
For use in animal feed products & 12 & 6.32 \\
For use in industrial products & 11 & 5.79 \\
For use in energy products & 8 & 4.21 \\
Research is valuable to production & 7 & 3.68 \\
Human benefits & 5 & 2.63 \\
[Commodity] contribute to Arkansas agriculture & 4 & 2.11 \\
For use in common household products & 3 & 1.58 \\
[Commodity]s are environmentally sustainable & 2 & 1.05 \\
Benefits Arkansas economy & 1 & 0.53 \\
Diversity of [Commodity]s & 1 & 0.53 \\
United [Commodity] Board Check-off & 1 & 0.53 \\
Total & 160 & 100.00 \\
\hline
\end{tabular}

\section{Content and Visual Message Consistency}

To evaluate the consistency of the content message compared to the visual message, researchers compared the implied content and visual message. In the communications pieces targeted to the general public, 22 of the 32 analyzed promotional pieces consistently communicated the message intended by TPCG as stated in its outlined communications plan (Table 7). Nine of the 19 promotional pieces targeting the [commodity] producers consistently communicated the intended message outlined by TPCG. Four of the eight promotional pieces targeting animal agriculture consistently communicated the message outlined by TPCG.

Table 7

Content Message Consistency Based on Outlined Message as Compared to the Intended Message for the Target Audience Groups (N =53)

$\begin{array}{ccc}\text { General Public } & \text { [Commodity] Producers } & \text { Animal Agriculture Producers } \\ (n=32) & (n=19) & (n=8)\end{array}$

\begin{tabular}{lcccrcr} 
Message & $n$ & $\%$ & $n$ & $\%$ & $n$ & $\%$ \\
\hline Consistent & 22 & 68.75 & 9 & 47.37 & 4 & 50.00 \\
Inconclusive & 9 & 28.13 & 9 & 47.37 & 4 & 20.00 \\
Inconsistent & 1 & 3.12 & 1 & 5.26 & 0 & 0.00 \\
Total & 32 & 100.00 & 19 & 100.00 & 8 & 100.00 \\
\hline
\end{tabular}

Note. Inconclusive means there was no intended message for comparison. 
communicated the message outlined by TPCG in their communications plan (Table 8). Fifteen of the 25 visual promotional pieces targeting [commodity] producers consistently communicated the message originally outlined. Seven of the nine promotional pieces targeting animal agriculture producers consistently communicated the message originally outlined by TPCG.

Table 8

Visual Message Consistency Based on Outlined Message as Compared to the Intended Message for all Target Audiences ( $\mathrm{N}=53)$

$\begin{array}{ccc}\text { General Public } & \text { [Commodity] Producers } \\ (n=24) & \text { Animal Agriculture Producers } \\ (n=25) & (n=9)\end{array}$

\begin{tabular}{lcccccc} 
Message & $N$ & $\%$ & $n$ & $\%$ & $n$ & $\%$ \\
\hline Consistent & 16 & 66.67 & 15 & 60.00 & 7 & 77.78 \\
Inconclusive & 4 & 16.67 & 7 & 28.00 & 2 & 18.18 \\
Inconsistent & 4 & 16.67 & 3 & 12.00 & 0 & 0.00 \\
Total & 24 & 100.00 & 25 & 100.00 & 9 & 100.00 \\
\hline
\end{tabular}

Note. Inconclusive means there was no separate message for comparison.

\section{Conclusions and Recommendations}

The findings of this study showed that many of the promotional pieces analyzed displayed a multitude of marketing themes, and in some instances did not accurately represent the intended message according to the original communications plan. This general conclusion can be partially explained and by Caywood and Langrehr's (1995) notions that advertising is susceptible to communicating mixed signals or messages and that organizations cannot solely rely on third-party communications groups, working as a mediators, to interpret the message as would the audience. McQuail's (2005) view on message oversaturation was also supported by this study. That is, when mass communication messages are repurposed in identical forms, the result can be oversaturation in the media and loss of uniqueness.

The content analysis showed that among the creative pieces targeted toward the three audience segments, there were as many or more communicative themes present as there were creative pieces. In the case of the promotional pieces targeting animal agriculture producers, there were two communicative themes per promotional piece. With so many messages present, McQuail's (2005) oversaturation concept most certainly applied. However, unlike McQuail's explanation, the oversaturation problem in this campaign was not because of over-repetition of a few key messages, but instead the problem was the use of far too many messages, which may have contributed toward diluting the power of the campaign.

While the audience segments had differing demographics and, therefore, were purposefully targeted with different messages, there appeared to be little cohesion across the campaign as a whole. For example, the top five emergent themes in the communications pieces targeting the general public were predominantly different than the themes identified in the [commodity] and animal agriculture producers' audience. Only two themes were identified in all three audiences: (1) promotion of [commodity] board and (2) for use in food products. The [commodity] producers and animal agriculture producers groups' top five emergent themes were almost identical, with only the 
fourth most saturated content theme differing. [Commodity]s contribute to animal agriculture was the fourth most saturated theme for [commodity] producers and promotion/use of slogan was fourth most saturated for the animal agriculture producers.

These findings logically lead to the recommendation to reduce the number of thematic messages in each promotional piece and the overall number of different themes in order to provide more focused, cohesive messaging based more closely on the campaign goals. According to Telg and Irani (2012), an effective and successful message is created based upon the goal of the promotional piece. In future promotional campaigns, more time should be spent developing simplified, audience-specific messages that represent only the most important campaign messages (Weinreich, 2011) rather than the broad plethora of messages observed in the 2012 campaign.

In this campaign, a local celebrity endorser was utilized to establish credibility (Weinreich, 2011) with the general public target audience. However, the celebrity's efforts may not have been effectively managed. Thus, the celebrity appears to have promoted his own image more than the $\mathrm{ACPB}$ or [commodity]. This conclusion is supported by the fact that the celebrity endorsement theme emerged 59\% more than the second most saturated theme in pieces targeting the general public audience. It is also recommended that commodity groups develop a strategic plan to ensure greater saturation of messages about the organization and its beliefs in conjunction with celebrity endorsements.

Visual analysis is another tool for "understanding perceptions, media influence, and agricultural portrayal" (Tolbert \& Rutherford, 2009, p. 18). Overall, the number of emergent themes and theme occurrences was lower in the visual analysis, most likely due to the difficulty of visually representing certain themes or messages. Still, the same issue of oversaturation via multiple message themes was present in the campaign's video pieces and images. Similar to the non-visual content, the visuals and videos included an average of one unique thematic message per creative promotional piece analyzed. However, the visual pieces did show more consistency across audience segments, with the top five emergent themes being similar across the visual pieces targeting the three audiences. Four emergent themes were identified in the three audiences: (1) promotion of [commodity] board, (2) grown in Arkansas, (3) how [commodity]s are produced, and (4) for use in food products. [Commodity]'s contribute to animal agriculture was a top-five emergent theme in the general public and animal agriculture producers audience and promotion/use of slogan was an emergent theme identified by the [commodity] producers audience. Another interesting observation was that only one reference was made to the national [commodity] checkoff in visual images targeted to each audience.

The campaign was able to integrate some level of consistency, judged by messages outlined in its original plan. However, several promotional pieces across all audiences lacked an outlined message in the original plan for comparison. This observation serves as a reminder to all communicators that not only should there be a clearly outlined communications plan (Snyder, 2003; Telg \& Irani, 2012), but the plan needs to be followed. Without clearly outlined communications objectives, key messages, campaign efforts have no logical basis for evaluation.

Among the textual content of all the promotional pieces evaluated, 59.32\% of the messages were consistent with the intended messages outlined in the plan, and only $3.39 \%$ of the messages were inconsistent. However, $37.29 \%$ of the messages were deemed as invalid and not eligible for evaluation in terms of consistency because though they were clearly key messages in the promotional pieces, they were not outlined in the original plan. Among the visual images, iepress.org/jac/vol100/iss2/3 
$65.52 \%$ of the messages were consistent with the intended messages in the plan and only $12.07 \%$ were inconsistent. However, $22.41 \%$ of the messages were deemed as invalid and not eligible for comparison because there was no corresponding message or communications objective in the original plan. Finally, when the textual and visual messages were compared, only $48.39 \%$ of the messages were consistently complementary, which meant that $51.61 \%$ of those messages did not complement each other. In several promotional pieces, for example, one meaning was derived from the textual analysis, while a different message was derived from analysis of the visual message. For example, in a print advertisement, the textual message of the print advertisement was more focused on biodiesel and the economy, while the visual message was more focused on animal agriculture. Inconsistency between the two categories could be a result of the difficulty to support various messages through visual (e.g., benefits Arkansas' economy, economic value to consumers, and value of educating about [commodity]s). These conclusions strengthen the recommendations that (1) future campaign plans should focus on consistent, integrated messaging across media-both textual and visual and (2) that all media efforts should be concretely linked to one or more of the communication objectives.

To determine the effectiveness or success of a campaign, every aspect of a campaign should have a form of evaluation (Weinreich, 2011). Significant time should be spent developing simplified, audience specific messages that represent the most important theme (Weinreich, 2011). If an audience's demographics and psychographics can be determined, proper development of persuasive targeted messages can be achieved (Telg \& Irani, 2012). The purposes and goals of promotional pieces should be the first considerations in the development process, and key campaign messages should (a) be developed from two or three key points that support message theme, (b) be presented in order of importance, with the most important information listed first, and (c) utilize visual devices such as logos, color, and others to gain and retain audience attention (Telg \& Irani, 2012).

For some public communications efforts, an expert in the field is often used as a "gatekeeper" (Shoemaker, 1991; Telg \& Irani, 2012; Weinreich, 2011) for technical information being communicated to the public. A gatekeeper should possess extensive knowledge of the subject matter or audience to ensure appropriateness of materials. This individual would be responsible for reviewing or testing any materials intended to target an audience to identify any errors before promotional materials are distributed to audience members (Weinreich, 2011). Shoemaker (1991) suggested utilizing more than one gatekeeper to avoid individualization of decision-making. The [commodity] board would benefit from a gatekeeper-someone with an understanding of [commodity] production and marketing as well as marketing communications- to review and approve all creative pieces disseminated by the TPCG.

Little research on visual analysis and more specifically visual analysis in marketing exists. This study was a first step in highlighting the importance of both image-based and marketing assessment research in agricultural communications. Evaluation through textual and visual analysis should continue to progress in the agricultural marketing sector (Tolbert \& Rutherford, 2009).

\section{References}

Agrawal, J., \& Kamakura, W. (1995). The economic worth of celebrity endorsers: An event study 
analysis. The Journal of Marketing, 59(3), 56-62.

Arkansas Farm Bureau. (n.d.). Arkansas Farm Bureau - The Voice of Agriculture for Arkansas.

Available at http://www.arfb.com/education-youth/ag-classroom/default.aspx

Arkansas [Commodity] Promotion Board [ACPB]. (2011a). Checkoff at work. Available at http:// www. [xxxxxxxxxxxxxx].com/checkoff-work

Arkansas [Commodity] Promotion Board [ACPB]. (2011b). Overview. About The Arkansas

[Commodity] Promotion Board. Available at http://www.[xxxxxxxxxxxxxx].com/

Armstrong D., Gosling A., Weinman J., \& Marteau, T. (1997). The place of inter-rater reliability in qualitative research: an empirical study. Sociology, 31(3), 597-606. doi:10.1177/0038038597031003015

Berger, C., \& Chaffee, S. (1987). Handbook of communication in science. Beverly Hills, CA: Sage Publications.

California Milk Advisory Board [CMAB]. (2013). About Us. Mission of the CMAB. Available at http://www.realcaliforniamilk.com

Caywood, C. L., \& Langrehr, F. W. (1995). A semiotic approach to determining the sins and virtues portrayed in advertising. Journal of Current Issues and Research in Advertising. 17(1), 33-47. doi:10.1080/10641734.1995.10505024

Cotton Incorporated. (2013). The fabric of Hayden's life. Available at http://www. thefabricofourlives.com/campaign.html

Doerfert, D. L. (Ed.) (2011). National research agenda: American Association for Agricultural Education's research priority areas for 2011-2015. Lubbock, TX: Texas Tech University, Department of Agricultural Education and Communications.

Edgar, L., \& Rutherford, T. (2012). A semiotic analysis of a Texas Cooperative Extension marketing packet. Journal of Applied Communication, 96(1), 15-28.

Frick, M. J., Birkenholz, R. J., \& Machtmes, K. (1995). Rural and urban adult knowledge and perceptions of agriculture. Journal of Agricultural Education, 36(2), 44-53. doi:10.5032/ jae.1995.02044

Gall, M. D., Gall, J. P., \& Borg, W. R. (2006). Educational research (8th ed.). Upper Saddle River, NJ: Pearson Education, Inc.

Gibbs, G. R. (2007). Analyzing qualitative data. In U. Flick (Ed.). The Sage qualitative research kit. London: Sage.

Hanstén, S. (2009). Defining successful marketing communication: A follow-up of a global campaign. University of Applied Sciences. Available at http://publications.theseus.fi/ bitstream/handle/10024/6324/Hansten_Susanna.pdf?sequence=1

Igo, C., \& Frick, M. (1999). A case study assessment of standard and benchmarks for implementing food and fiber systems literacy. Proceedings of the 18th Annual Western Region Agricultural Education Research Meeting, 218-229.

Kamins, M., Brand, M., Hoeke, S., \& Moe, J. (1989). Two-sided versus one-sided celebrity endorsements: The impact on advertising effectiveness and credibility. Journal of Advertising, 18(2), 4-10. doi:10.1080/00913367.1989.10673146

Khatri, P. (2006). A celebrity endorsement: A strategic promotion perspective. Indian Media Studies Journal, 1(1), 25-37.

Knapp, D. (1999). The brand mindset. New York, NY: Mc-Graw Hill.

Laczniak, R. N., \& Muehling, D. D. (1993). Toward a better understanding of the role of 
advertising message involvement in ad processing. Journal of Psychology and Marketing. 10(4), 301-319. doi:10.1002/mar.4220100405

Lester, P. (2011). Visual communications: Images with messages. Belmont, CA: Wadsworth Publishing.

Lincoln, Y. S., \& Guba, E. G. (1985). Naturalistic inquiry. Newbury, Park, CA: Sage Publications. Lutz, C., \& Collins, J. (1993). Reading national geographic. Chicago, IL: University of Chicago Press.

MacDonald, L., Perry, J., Ahearn, M., Banker, D., Chambers, W., Dimitri, C., Key, N., Nelson, K., \& Southard, L. (2004). Contracts, markets, and prices: Organizing the production and use of agricultural commodities. Agricultural Economic Report, 837.

Manghani, S. (2013). Image studies: Theory and practice. New York, NY: Routledge Publishing. Marshall, G., \& Johnston, M. (2010). Marketing management. Boston, MA: McGraw-Hill Irwin. McMillan, J., \& Schumacher, S. (2010). Research in education. Upper Saddle River, NJ: Pearson. McQuail, D. (2005). Mass communication theory. Thousand Oaks, CA: Sage Publications. Patton, M. (1982). Practical evaluation. Beverly Hills, CA: Sage Publications.

Reidel, J., Wilson, E., Flowers, J., \& Moore, G. (2007). Effects of an introductory agricultural education course on agricultural literacy and perceptions of agriculture in urban students. Journal of Southern Agricultural Education Research, 57(1). Available at http://pubs.aged.tamu. edu/jsaer/pdf/Vol57/57-01-082.pdf

Rhoades, E. B., \& Irani, T. (2008). The stuff you need out here: A semiotic case study analysis of an agricultural company's advertisements. Journal of Applied Communications, 92(3-4), 33-46

Rice, R. E., \& Atkin, C. K. (Eds.). (2013). Public communication campaigns. Thousand Oaks, CA: Sage.

Rose, G. (2001). Visual methodologies. Thousand Oaks, CA: SAGE Publications Inc.

Ryan, D., \& Lockaby, J. (1996). An assessment of the agricultural literacy level of city and government leaders. Proceedings of the Fifteenth Annual Western Region Agricultural Education Research Meeting, 96, 77-88.

Schlecht, C. (2003). Celebrities' impact on branding. Columbia: Columbia Business School. Available at http://worldlywriter.com/images/portfolio/Proposals/Celebrity_Branding.pdf

Shoemaker, P. J. (1991). Gatekeeping. Thousand Oaks, CA: SAGE Publications Inc.

Snyder, L. (2003). Chapter 10: Development communication campaigns. In International and development communication: A 21st-century perspective. Thousand Oaks, CA: Sage Publications, Inc.

Telg, R., \& Irani, T. (2012). Agricultural communications in action: A hands-on approach. Clifton Park, NY: Delmar.

Third Party Communications Group [TPCG]. (n.d.) Who are we? Available at http://www. [xxxxxxxx].com/who-are-we.html

Tolbert, J., \& Rutherford, T. (2009). A semiotic analysis of biotechnology and food safety images in Time, Newsweek and U.S. News \& World Report. Journal of Applied Communication, 93(12), 6-20.

Weinreich, N. K. (2010). Hands-on social marketing: A step-by-step guide to designing change for good. Thousand Oaks, CA: Sage Publications.

Wimmer, R. D., \& Dominick, J. R. (2003). Content Analysis. Mass Media Research: An introduction (7th ed., pp. 140-162). Belmont, CA: Wadsworth/Thompson Publishing. 


\section{About the Authors}

Amy Hughes is a MS graduate from the Department of Agricultural Education, Communications and Technology (AECT), and currently works as a market research analyst for JB Hunt.

Tara L. Johnson is a Walmart Project Manager II, Merchandise Execution. She is a former AECT graduate assistant and a University of Arkansas MS graduate.

Leslie D. Edgar is a professor at the University of Arkansas in the Department of Agricultural Education, Communications and Technology. She also serves as the Assistant Dean of Student Programs for Bumpers College. Dr. Edgar has been an ACE member since 2006.

Jeff Miller, a professor of agricultural communications, is a long-time ACE member. He teaches and conducts research in agricultural communications at the University of Arkansas.

Casandra Cox is an agricultural communications instructor at the University of Arkansas. 